\title{
WestVirginiaUniversity
}

THE RESEARCH REPOSITORY @ WVU

Graduate Theses, Dissertations, and Problem Reports

2021

\section{Non-monetary Economies: A Study on Different Governing Principles}

\author{
Richard Perry Vest II \\ West Virginia University, rpv0001@mix.wvu.edu
}

Follow this and additional works at: https://researchrepository.wvu.edu/etd

Part of the Economic Theory Commons

\section{Recommended Citation}

Vest, Richard Perry II, "Non-monetary Economies: A Study on Different Governing Principles" (2021). Graduate Theses, Dissertations, and Problem Reports. 8246.

https://researchrepository.wvu.edu/etd/8246

This Thesis is protected by copyright and/or related rights. It has been brought to you by the The Research Repository @ WVU with permission from the rights-holder(s). You are free to use this Thesis in any way that is permitted by the copyright and related rights legislation that applies to your use. For other uses you must obtain permission from the rights-holder(s) directly, unless additional rights are indicated by a Creative Commons license in the record and/ or on the work itself. This Thesis has been accepted for inclusion in WVU Graduate Theses, Dissertations, and Problem Reports collection by an authorized administrator of The Research Repository @ WVU. For more information, please contact researchrepository@mail.wvu.edu. 
Non-monetary Economies: A Study on Different Governing Principles

\section{Richard Vest II}

Thesis submitted

to the Davis College of Agriculture, Natural Resources and Design

at West Virginia University

in partial fulfillment of the requirements for the degree of

Master of Science in

Energy Environments

Xiaoli Etienne, Ph.D., Chair

Jason Hubbart, Ph.D.

Peter Schaeffer, Ph.D.

Division of Resource Economics and Management

Morgantown, West Virginia

2021

Keywords: Non-monetary, Economy, Economics, Automation, Utility

Copyright 2021 Richard Vest II 


\section{Abstract \\ Non-monetary Macroeconomies a Study on Different Governing Principals}

\section{Richard Vest II}

This thesis examines a new economic system with a focus on non-monetary (primarily automation) aspects. Currency has been used in exchange for goods and services and this exchange has often resulted in benefits gained by any given individual. What if that wasn't the case? How might society function if it was not influenced by currency? This thesis explores this hypothetical concept of an economy without currency with a focus given to automation. Using utility and production functions, discussion is given on how supply and demand functions behave in a non-monetary economy, how governing policy could be handled, and how society could function with the normalization of not having currency as the leading regulation factor. Results of this discussion give focus to a life of leisure in a utopian society due to the assumptions needed to sustain it. These examples of government and society are intended to act as a possible foundation for future research into this type of economy and similar topics. 
Table of contents

Non-monetary Economies: A Study on Different Governing Principles .................................. i

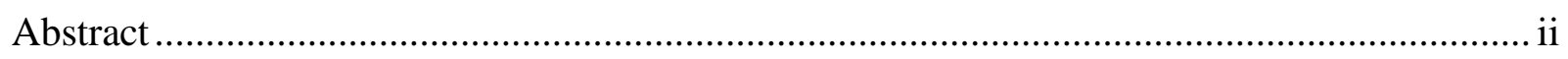

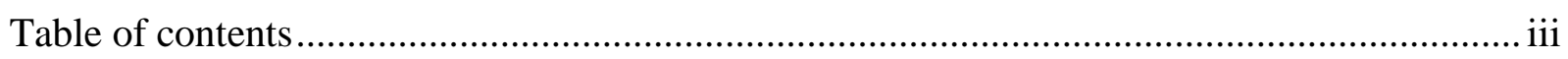

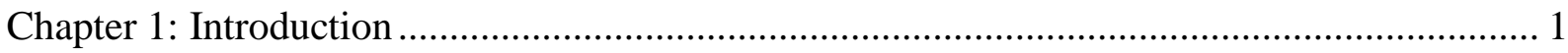

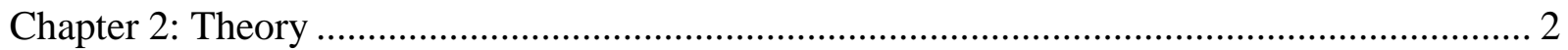

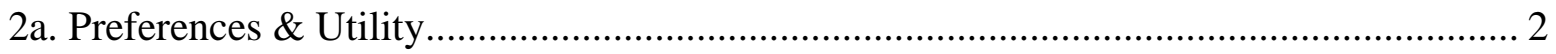

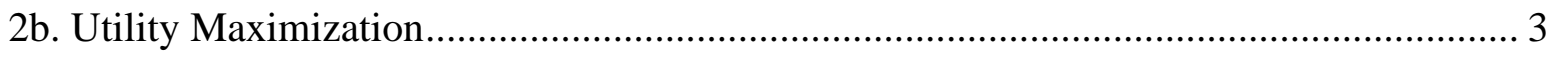

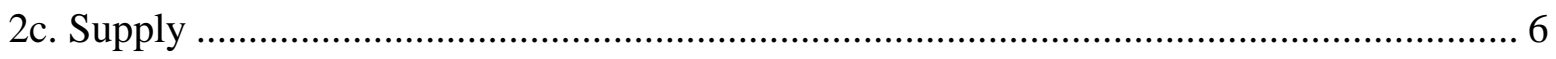

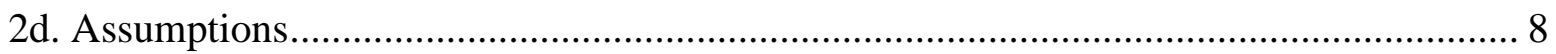

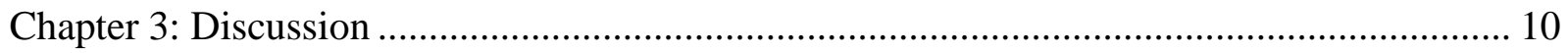

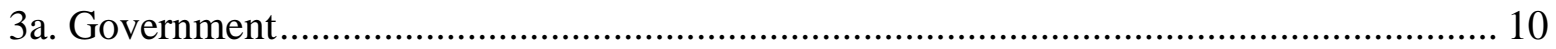

3b. Society Function .............................................................................................. 13

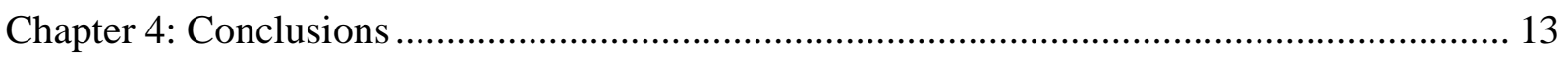

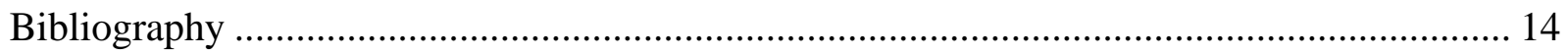




\section{Chapter 1: Introduction}

The purpose of this research was to explore the possibility of a non-monetary economy and its implications for governing policies. As civilizations continue to progress, the people see changes in the ways in which they function, but they tend to have a consistent way to regulatethe use of currency to assign valuations to goods. A society without monetary valuations assigned to things can present many issues, from lack of supply to diminishing resources. In an economy where goods are supplied without monetary cost (or cost in any other forms) and work no longer adds wage as a way of purchasing, individuals would have little incentive to work. This would leave machines to produce all necessary goods as a large portion of production from labor needs to be substituted. It could be possible to reach full-scale automation in the future as sectors continue to transition from workers to machines (Yarlagadda, 2017). In recent years, automation has been increasing at faster rates, partially due to COVID-19 (Chernoff \& Warman, 2020). A society without monetary valuations attached to goods may become a possibility in the future.

The current literature has many different versions of economic structures that are similar to the non-monetary economies discussed in this work. The theory of surplus value, populated by Karl Marx, argues that the difference between the market price of the commodity and the cost used to produce the good, is one of the driving forces to conflicts among different classes (Marx $\&$ Engels, 1883). While generating increasing income for the capitalists (bourgeoisie), the surplus value gives diminishing returns to the workers (proletariat). The increasing differences between the wealths held by capitalists and workers gives rise to class conflicts, tensions, and economic crisis. Instead of promoting maximum profit and productivity, Marx believes that the ideal social system should empower the workers and let workers control their own lives (Marx \& Engels, 1883). The Marxist theory has heavily influenced the Socialism movement. Kolb (Kolb, 2007) notes that although there are many forms of socialism, they all eliminate private ownership of capital and are in favor of collective ownership. In particular, the non-market socialism proposes substituting factor markets and money with integrated economic planning, thereby removing the use of money and prices in the economic system (Bockman, 2011). Another increasingly popular idea closely relates to the economic structure presented in this study is "paradism." In a paradist system, all production takes place by robots, nanorobots, and computers, while individuals are only involved in activities that they enjoy. Paradism has limited information on it and its development is mostly in the idea phase.

This study will use some economic models with various assumptions to show one path that a non-monetary economy could take. In a non-monetary economy, although goods still have instrinc values, they are supplied without monetaty valuations and individuals no longer need to pay to consume goods. Since goods are provided free of charge, the amount of people willing to work will dramatically decrease, with the majority people engaging in activities that fullfill personal pursuits. This research will explore policy options supported by the economic models for this specific society. In the following chapters, the supply and demand functions are formulated, followed by discussions on policies that would support the functionality of a non-

\footnotetext{
${ }^{1}$ See https://paradism.org/ for details on paradism.
} 
monetary economy. This will give perspective into a non-monetary economy and whether it would be sustainable.

\section{Chapter 2: Theory}

\section{2a. Preferences \& Utility}

In an economy supply and demand are among the fundamental building blocks. Starting the discussion using food as a general example. Although food can be of many types, for our purposes, it is treated as single resource. When people consume food, they benefit from it, while some people might gain more or less benefit than others. This is commonly known as "utility" in economics. People, in general, like to have more benefits, so ideally having more food would mean a higher level of benefits. This is true to an extent. After someone eats food, they might become satisfied, but they might be willing to eat more. Once they have more food, they might feel bad physically because they ate too much. When offered more food they might decline because eating any more would decrease their happiness (or utility) level. This shows the principle of diminishing marginal utility - more is better, but the marginal gains decline as the unit of consumption increases.

The diminishing marginal utility definition is closely linked to the concept of diminishing marginal rate of substitution. Assume the level of satisfaction can be represented by mathematical expressions, or utility functions. Further assume the utility function is convex and continuous, the amount of good 1 an individual is willing to give up in exchange for one more unit of good 2, while maintaining the same level of utility, declines as they have more and more of good 2. In other words, the marginal rate of substitution between goods 1 and 2 decreases in the amount of good 2.

Consider, for example, an individual facing the choices between apples and oranges, as shown in figure 1. In this example we will assume consumers prefer oranges over apples and they also enjoy variety. With 10 oranges, they are satisfied. If we were to take an orange away, how many apples would this individual need to keep them just satisfied as 10 oranges? In this case, assume 2 apples are sufficient. The individual now has 9 oranges and 2 apples, and they are at the same level of satisfaction. The marginal rate of substitution between apples and oranges is

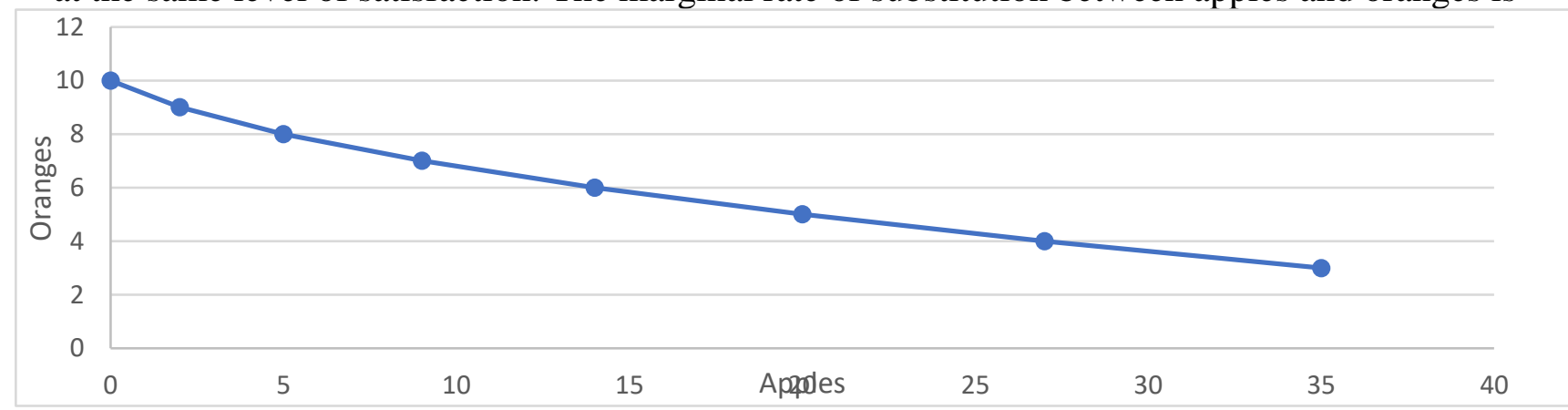

Figure 1. Consumption of Applies and Organges

2, when the individual has 10 apples. Taking another orange away, this time the individual requires 3 more apples to remain at the same level of satisfaction. In other words, the marginal 
rate of substitution between apples and oranges is 3 when the individual has 9 oranges. In general, a well-behaved utility function implies that it takes more and more apples to remain at the same level of satisfaction as we decrease the number of oranges we have.

The examples have shown how consumers want to have more of something to an extent and that they have preferences. Those preferences shape their choices of goods and satisfy the following assumptions: 1) completeness, 2) monotonicity, 3) transitivity.

We can now look at the specific mathematical representation of utility functions. In a monetary society, i.e., a society regulated by currency exchange, utility can be written as a function of real wealth $(W)$, as in equation (1):

$$
\text { utility }=U(W) \text {. }
$$

Wealth generally does not generate utility directly; instead, it creates utility indirectly by giving the person the ability to purchase consumption goods that increases their levels of satisfaction. Real wealth can be substituted by the amount of goods individual consumers, which are denoted by " $x 1$ " and " $x 2$ " here in the case of two goods. Rewrite the utility function as in equation (2):

$$
\text { utility }=U(x 1, x 2)
$$

where $\mathrm{x} 1$ and $\mathrm{x} 2$ are the amount of good 1 and good 2 consumed, respectively.

In a non-monetary economy, people still have preferences and they still gain utility from those goods. In general, utility from the consumption of goods should remain the same. These utility functions are again assumed to be continuous, convex, and twice differentiable. The utility function can be plotted as in figure 2 , which are referred to as the indifference curve in economics.

The slope of the indifference curve represents the marginal rate of substitution, or the amount of good 2 that the individual is willing to give up in exchange for one more unit of good 1, while remaining at the same level of utility. Further, any combination of two goods on a given indifference curve represents the same level of utility, and

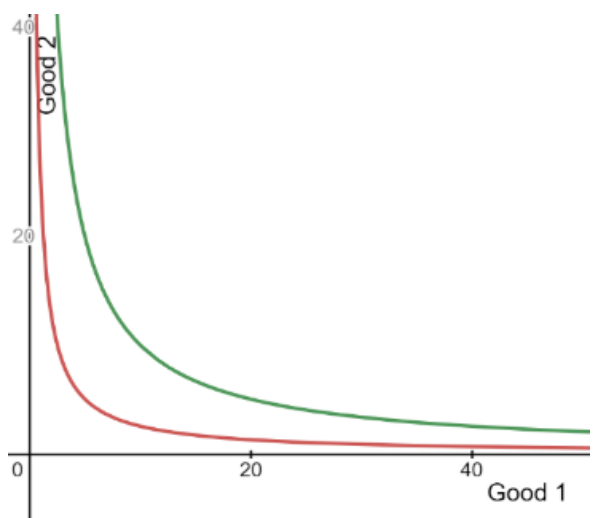

Figure 2. Indifference curves the indifference curve to the right always has a higher level of utility than those to the left.

\section{2b. Utility Maximization}

In a monetary economy a consumer receives currency to exchange for consumable goods. These currencies could come from, for instance, employment wages. As such they have a budget that determines a combination of goods that will maximize their utility. This simultaneously restricts them from consuming larger bundles and indirectly prevents supply depletion or a tragedy of the commons. It also helps regulate items society deems undesirable. In the economy 
with currencies, individuals typically try to maximize their utility with the constraint being income.

Consider a bundle of two goods, the budget constraint can be written as in equation (3):

$$
I=p_{1} x_{1}+p_{2} x_{2}
$$

where $I$ is income to be spent on the two goods, $p$ is the price of a good, and $x$ is the amount of the good. Figure 3 provides an example when the individual has a budget of $\$ 10$, and the price of goods 1 and 2 are $\$ 1$ and $\$ 2$ per unit, respectively. The budget equation becomes

$$
10=x_{1}+2 x_{2},
$$

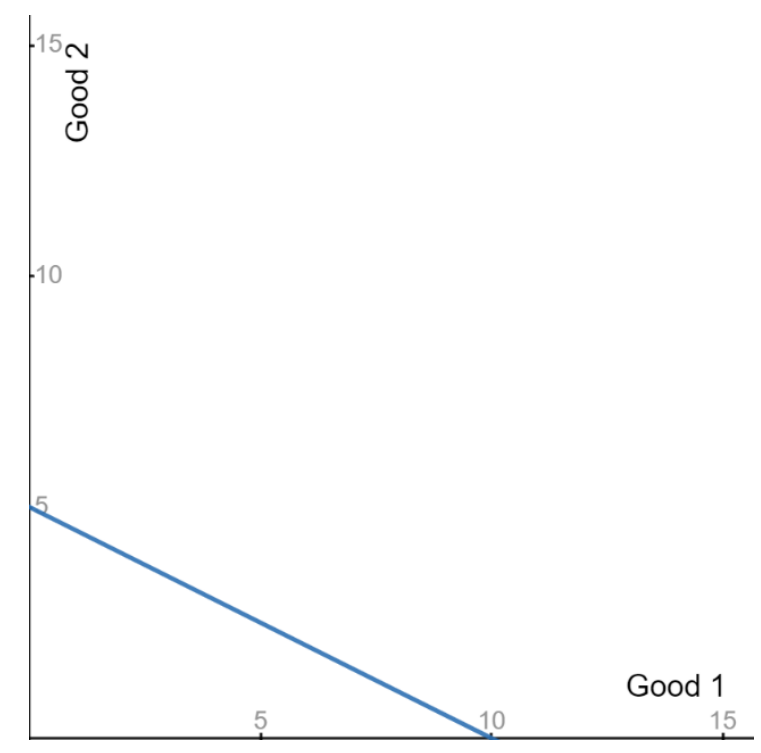

Figure 3. Budget Constraint for Individuals in a Monetary Economy

As can be seen in figure 3, if the individual spends all income on Good 1 then they will receive 10 units of good 1. Meanwhile, spending all of income on Good 2 will give the individual 5 units of good 2. In this case the individual has access to any combination of goods that are under or on the line, while anything to the right of the line is not possible due to the budget constraint. The slope of the budget constraint represents the amount of good 2 the individual must give up in exchange of one more unit of good 1 while remaining at the same level of budget. If we overlay the budget constraint with the indifference curves in figure 2 , we have the utility maximization representation: 


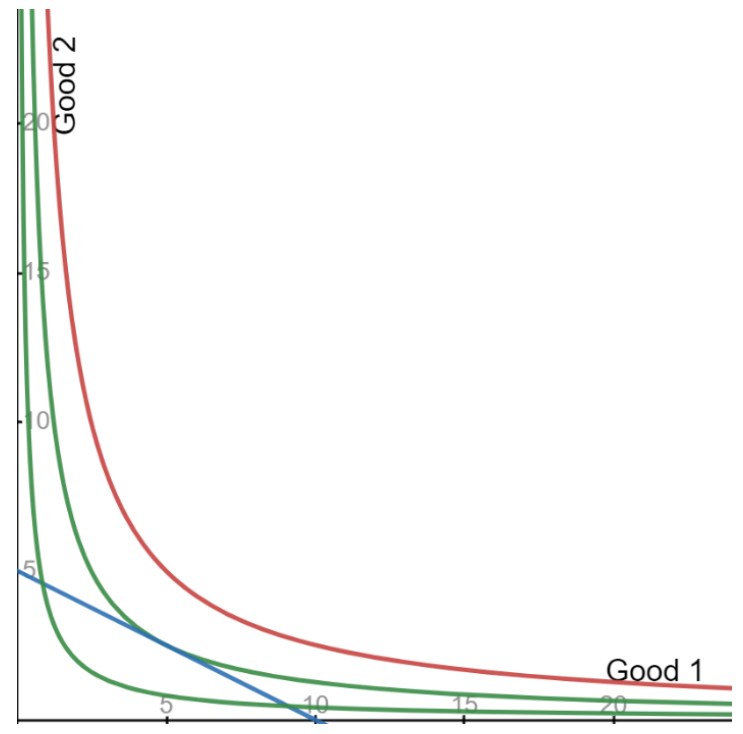

Figure 4 Utility Maximization Problem in a Monetary Economy

As can be seen in figure 4, to maximize the utility, a consumer chooses a combination of two goods at which an indifference curve is tangent to the budget line. This point is where all available funds are spent and the psychological trade-off (marginal rate of substitution) is equal to the rate at which the goods can be traded on the market. The budget regulates the quantity of any given good with respect to the individual's utility maximization. In other words, the individual is limited to a combination of goods that are within that individual's budget. Anything outside the budget is unreachable.

One key question here relates to the amount available to spend by consumers, the income in equation (4). Income can come from a variety sources, including employment wages, government subsidies, gifts, etc. However, for most consumers, employment wage represents most income. In a monetary economy, individuals choose to work to accumulate income, which can be spent on physical goods to increase their level of satisfaction.

With a non-monetary economy, a budget based on currency is eliminated and another form of a budget could take its place. Goods will be provided at a zero monetary cost. Since individuals could obtain goods for zero monetary cost, and the supply of those goods is steady, then there is no need to work to generate income to buy consumable goods. How would a person maximize their utility? This is essentially equivalent to the case that the individual has an unlimited budget in the monetary economy and can consume as many units of goods as they desire, provided there are sufficient supplies. As such, it is almost an exact opposite scenario as figure 4-there is no way of regulating consumption for any given good. We are open to supply depletion and consumption of undesirable goods. Without a budget, we return to the only things that will limit consumption - the declining marginal utility/marginal rate of substitution, as in figure 2, and supply (to be discussed in the next section). The marginal utility will only be positive to a certain extent before becoming negative, making an overall utility maximum for the consumer. 


\section{2c. Supply}

Supply is largely determined by the relationship between inputs and outputs, as shown in equation (4):

$$
q=f(k, l, m, \ldots)
$$

where $q$ represents the firm's output of a particular good during a given period, $k$ represents the machinery (capital) usage during the period, $l$ represents hours of labor input, and $m$ represents raw materials used. There is also the possibility of other variables in the production function. A simplified production function can be used for the purposes of this paper, as shown in equation (5):

$$
q=f(k, l) .
$$

Like the marginal utility for the utility function, a production process has marginal product, or the additional amount of output that will be produced if one more unit of a given input is used, while holding the number of other inputs constant. In this case, both capital and labor have a marginal product, or the rate at which the production is increased by using one more unit of capital or labor, holding everything else constant. Just like marginal utility, the marginal product has a point to which it becomes diminishing to the product production.

In a monetary economy, the amount of labor available is largely determined by the need to attain income. As discussed in Chapter 2(b), individuals choose to work to obtain income, so that they can purchase goods that increases their utility. With a non-monetary economy, people no longer need to work as consumer goods no longer have monetary valuation, i.e., they are not required to pay for goods with currency (or any other forms of payment); they can simply pick them up from a location without any cost. Essentially, in this case, stores would become more like warehouses. The problem occurs with supplying those goods. As people would ideally not need to work, and we assume they have the supply necessary, they would live a life focused on leisure. Therefore, the production function changes where the quantity of any good is entirely dependent on capital, as in equation (6):

$$
q=f(k)
$$

In this case, we eliminate labor as a variable in production. With this variable eliminated, we would direct all production to machines. Although far from being accomplished, we can see a trend in the world today with direction towards automation. If we look back through history, jobs done by humans have largely been replaced by machine systems. Car assembly, for example, was once largely done by workers assembling the parts manually. Now there are very few workers on a car assembly line that are for assembling parts. Robots programmed with extreme precision have replaced those positions as the main contributors of car assembly. Workers are still used for some part assembly and detailing. Driving cars is also slowly becoming more automated. Though we are decades away from having fully automated driving cars, we do have prototypes being worked on. Artificial intelligence (AI) has also been in development in the past decade. As technology advances, we no longer require work done in certain areas by humans. Not all work is replaced by machines, but some areas are replaced. 
A current example of how automation is affecting daily life is automation in restaurants. In Chicago there are $10 \mathrm{McDonald}$ 's restaurants testing automated drive-thru ordering. CEO Chris Kempczinski said the voice-ordering technology was about $85 \%$ accurate on the orders. Only about a fifth of orders needs to be taken by a human at those locations. He also added that the technology wouldn't likely roll out within the next five years even though they have the technology to do so now. The investment costs are too much when considering that the labor cost is much cheaper (Lucas, 2021). They are using it small scale right now but they would probably like to implement it in the future when the cost of automation becomes lower. It might also be in development due to people demanding higher pay (Lichtenberg, n.d.).

In June of 2019 Oxford Economics published a report estimating that there will be as many as 20 million additional manufacturing jobs displaced by the year 2030 as a result of robotization. The report mentions three reasons why there is a robot surge taking place before covid-19 was an influential factor. The first reason is "Robots are becoming cheaper than humans". The second reason is "Robots are rapidly becoming more capable". The third reason is "Demand for manufactured goods is rising, and China is investing in robots to position itself as the global manufacturing leader"(Report - How Robots Change the World.Pdf, n.d.).

One question to consider is whether replacing labor with technology would increase or decrease production relative to the amount of labor used. In a non-monetary economy, their technology would have to be highly advanced to keep up with the production lost from labor. Even the most basic jobs would need to be replaced by machines to reach every phase of production reliably. It is possible that the society using this method would not have had the technology initially, but they could have gained it as time progressed. With COVID-19 becoming a major influence on companies to invest in automation we might see a new era of automation within the next few decades. Companies that have displaced workers due to the automation process hope to reposition them into higher paying jobs with certifications (Semuels, n.d.).

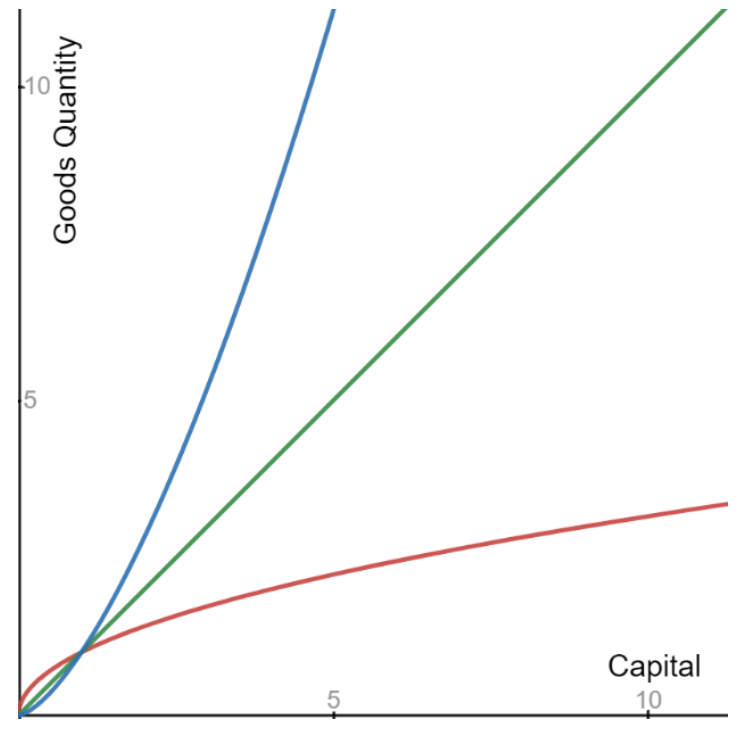

Figure 5. Production function with different returns to scale 
Figure 5 plots the production function with different returns to scale in a non-monetary economy, with capital as the only input. The red line indicates decreasing returns to scale which means a percentage increase in capital will produce a smaller percentage increase in output. The green line indicates constant returns to scale which means a percent change in capital will result in the same percent change in output. The blue line indicates increasing returns to scale which means a percent change in capital will result in a larger percent change in output. Ideally, production technology would display increasing returns to scale, at least within certain ranges of capital, to produce sufficient goods in a non-monetary economy.

Now assuming all production is taken care of, we can look at the effect it would have on the quantity supplied and demanded in the market. In both the short and long runs, in this type of economy supply will always meet demand when there are sufficient resources, with the effective price being zero. This is also when the maximum quantity is demanded. This is in sharp contrast to a monetary economy, where prices are rarely zero as the firms in the economy would not be sustainable. Simply put, in a monetary economy firms are not equipped to handle the quantity demanded at the price of zero. The production is centered around two values and production facilities adjust their production based on these values - the first value is the price for the item and the second value is the cost it takes to produce that item.

In a non-monetary economy, there is no cost, nor is there a value associated with the item. Supply will always meet demand and price is zero. This is similar to the "free goods" definition in economics - "Free goods are 'goods,' whether the consumer goods or productive inputs, which are useful but not scarce; they are sufficiently abundant supply that all agents can have as much of them as they wish at zero social opportunity costs (Steedman 1989)" However, it is possible that some goods have a positive social opportunity cost but a zero price due to a lack of property rights or because they are fully subsidized (Steedman 1989).

What does the non-monetary nature of the economy mean for the resources that are nonrenewable? Without monetary valuations associated with the resource, it would inevitably deplete at a much faster rate than in the monetary economy. For renewable resources, the replacement will come at a much faster rate to meet the production demand. In such case, individuals would have to find a way of making everything sustainable, including current nonrenewable resources if those resources are used. If we picture that the resources individuals had were abundant or easily accessible, then the value of their goods would decrease to zero. It would be like trying to sell a bottle of water to someone who can easily grab a bottle of water for free. You no longer have monrtary valuation in the bottle of water because it is no longer difficult to get. It should be noted that no exchange or barter system is needed in this type of economy - everything will be supplied without cost and there is abundant of goods available for consumption. Further, all goods produced would need to be of equal quality to any other that exists otherwise a greater quality good would have more value.

\section{2d. Assumptions}

The discussion on the supply and demand in the previous sections suggests that the supply of goods and services would need to be fully available at all times in this version of a non-monetary economy. How this could be accomplished is uncertain. Society could try 
widespread production facilities or supply facilities throughout the area for everything that the people would want. The resource use, in this case, would be extreme and unlikely to be sustainable. Another option would be to have the ability to produce the goods or services individuals need through highly advanced and efficient technology. Technology, in this instance, could be instant transportation to a location that has the good or service you need or instant transit of the good or service to you. The technology could also be matter conversion, which is a proven concept, but it requires an extreme amount of energy. If they were to go into matter conversion, the energy supply could be one of the few resources needed for that society to operate since everything you would need would be converted from energy.

We now have two assumptions. A non-monetary economy would need to 1) have all necessary resources sustainable and 2) have all products made from those resources easily accessible to consumers. Further, in this type of economy, society would need to rely on machines and technology for production and living needs. Unlike how our technology often was influenced by warfare as we often fought over resources, work for an individual in a nonmonetary economy would be through personal satisfaction and not related to the procurement of income. Work, in this case, would be more similar to a personal project than a career. Without the incentive/requirement for income, people would not seek to work as labor as it is no longer a variable in their utility.

Our technology and methods have advanced rapidly from wars because we needed them to adapt to various circumstances such as geography and climate. In the case of war, technology advances to meet the demand created by the circumstances. In a similar way, a non-monetary society would require the technology and methods to advance to meet the demands created by its unique circumstances. A monetary economy can convert over to a non-monetary economy successfully if the technology and methods can handle the stress of consumption. If the monetary economy cannot handle the stress of consumption, then the economy would collapse under the stress and it would most likely be considered a failure. Society would be hesitant to try again.

Based on the two assumptions of the non-monetary economy and the presentation above, we add the third assumption of the economy having advanced technology and methods to have resources sustainable and readily available. This is a very futuristic approach. It should also be noted that the economy loses the production it could gain from labor, but it makes up for this loss in advancement in technology and methods. By eliminating labor as a variable in the production function, we simplify most of the math used to determine how much the variable should be used.

In a monetary economy, consider the Cobb-Douglas production function, one of the most widely used production functions, as seen in equation (7):

$$
q=A k^{a} l^{b}
$$

where $\mathrm{A}$ is the total factor productivity, $\mathrm{k}$ is capital input, $\mathrm{a}$ and $\mathrm{b}$ are output elasticities, and $\mathrm{l}$ is labor input. Firms consider either the profit-maximization or cost-minimization problem:

$$
\begin{gathered}
\text { Revenue }=R=p q \\
\text { total cost }=C=w l+v k
\end{gathered}
$$




$$
\begin{array}{r}
\pi=R-C \\
\text { Or } \\
\pi=p q-w l-v k
\end{array}
$$

where $q$ is quantity, $p$ is price of the item, $w$ is the wage of labor, $l$ is labor hours, $v$ is the variable cost of capital, $k$ is capital hours.

In a non-monetary economy, the production function changes to the following:

$$
q=A k^{a}
$$

Notice 1 and $\mathrm{b}$ are no longer included due to production no longer requiring them as variables. Since technology and methods in a non-monetary economy would need to be advanced, it is also likely that the returns to scale would be constant or increasing. However, it is possible that the production function may display decreasing returns to scale for some range of inputs. Further, there is no cost associated with the inputs nor is there a price associated with the output. As the goal for suppliers is to simply meet the demand for all consumers, there is no maximizing point (although there might be maximizing output depending on the shape of the production function.) Cost-minimization could take the form of using the least amount of resources possible to be more efficient.

All of this leads us to the designation of a production facility. All facilities used for production would be from the public sector. There can be private-sector production facilities, but they would be used more for creative uses such as art and design and there would be no monetary gain from doing so.

\section{Chapter 3: Discussion}

\section{3a. Government}

Now we are assuming that the resources are sustainable and readily available, supply meets demand, and there is no monetary value for goods or resources. The government plays a major role in society and often influences features of an economic system both directly and indirectly. There are three main types of government policies that affect the economy. The policies are fiscal, monetary, and supply-side(Commonwealth Parliament, n.d.).

Fiscal policy in a monetary economy is used to change the level and composition of government spending as well as taxes. In a short summary they directly influence economic activity through capital expenditure and influence indirectly through effects of spending and taxes. The second major policy type is monetary policy. Monetary policy is an entire section of policy explicitly designed to control the value of the currency by lowering/increasing the supply of currency, which is done to control inflation/boost economy. Monetary policy mainly concerns with the amount of money in circulation, interest rates, and inflation. Neither fiscal policy nor monetary policy exists in a non-monetary economy (Commonwealth Parliament, n.d.). 
The third type is the supply-side policy. In a monetary economy these policies are designed to increase aggregate supply and increase productive potential. This includes privatization, cutting direct taxes, and generally improving methods of raising labor productivity. In a non-monetary economy, the supply-side policy would need to focus on improving efficiency and attempt to increase productivity in capital instead of labor. This can be achieved through an interventionist type of supply-side policies, where the focuses are on increasing education and training, improving transportation and infrastructure, building homes, and improving healthcare(Commonwealth Parliament, n.d.).

The supply-side policy is the only policy that would stay out of the three main economy policy types. Though the monetary version of this policy uses currency to pay for things, this would still be important for a non-monetary economy as well. In a non-monetary economy production would be focused primarily in these areas after consumer goods are met. Depending on the technology available the society might not have to spend as much in certain areas and could spend more in others(Commonwealth Parliament, n.d.).

In terms of general government functions, I will take the United States government branches as an example of how each branch would operate under a non-monetary economy. The United States has three main branches: Legislative, Executive, and Judicial. The legislative branch makes all laws, declares war, regulates interstate and foreign commerce and controls taxing and spending policies. The executive branch is responsible for enforcing the laws of the land. The judicial branch consists of the supreme court and other federal courts and their job is to rule on all matters related to law and the constitution(Branches of Government | House.Gov, n.d.). In the below sections, I briefly discuss how each branch of the government functions in a non-monetary economy.

\section{3a1. Legislative}

The legislative side of things would continue to function, though perhaps slightly differently. Laws focused around monetary value such as bankruptcy and tax would be eliminated. Some laws would remain relatively unchanged, such as civil rights law and criminal law, when compared to the judicial branch. It should be noted that there would likely be major changes to all laws in some way due to the primary regulation factor being changed. Some laws would change moderately such as business law. Business law would retain the management side, but the monetary side would be eliminated or changed. Since a lot of law has fines included to incentivize people to act a certain way, what do we replace it with? We do need some regulation factor to replace the monetary one, assuming people would retain their behavior for the most part.

Fines work as negative incentives to correct or change the way the population behaves. It is used to persuade the population not to do certain actions and change certain behaviors. When members of the population would commit an act or behavior that used negative incentives, and those members were caught doing that act or behavior, those members would have the negative incentives applied to them. If, for some reason, the members would not accept or resolve the negative incentives applied to them then the negative incentive would escalate and possibly lead to incarceration. 
For a monetary society it is easy to incorporate the primary regulation factor, currency, into both negative and positive incentives since currency directly relates to the utility an individual has. If the individual were to be fined, that individual would lose utility and therefor it would directly affect their life. For a non-monetary economy, you would need to utilize a similar method that would directly influence the individual's utility. Since currency is no longer a factor in their utility, perhaps something like hours of required community service could replace it. This would simultaneously provide utility to others while also providing the negative incentive to not act a certain way. The negative incentive, in this case, is decreased hours of leisure.

Although, with the assumption of advanced technology it's possible that some acts and behaviors would become prevalent due to the technology automatically resolving issues like cleaning up litter and clearing away smoke. Since the technology would automatically clean the area of pollutants then the act of polluting would no longer pose a threat to the environment and no longer cause negative opinion of the act as it would not directly affect others. It's possible that smoking would also no longer be a health risk, further increasing the act of smoking. Vaping was the most recent attempt at allowing people to smoke without the harmful effects however, there are still cases of lung problems associated with vaping. It is often considered safer than regular smoking but it's not risk free(Broderick, M.D., n.d.). This shows how advances in technology can provide healthier and safer ways of doing activities, which can also include industrial practices.

\section{3a2. Executive}

The executive side would continue to develop and change as needed with the economic system. The principle of the powers of each member could change slightly with perhaps more importance on disaster relief, new technology, and efficiency; with the highest priority being the welfare of the country's citizens. With regards to the military, it would remain the same depending on how widespread the area of effect for the non-monetization is. If the area of effect does not concern the entire world then an army will still be required. If the area of effect does cover the entire world then the principle regarding boundaries would cease to exist, meaning there would no longer be countries and instead there would be a single world organization. There might be areas defined for management needs but there would be no need for borders since each area would function more like a state within the country that is the world.

\section{3a3. Judicial}

The judicial side would have a lot of work to do, specifically regarding the supreme court. Many laws would be changed drastically including some constitutional law. Any law that involved monetary value would have to be reevaluated. This could be the most difficult thing to accomplish for the non-monetary economy. Due to previous rulings being canceled or overturned, it would lead to lots of conflict particularly with those involved in the rulings overturned. There could be a gradual progression from monetary to non-monetary which could alleviate the pressure but to do so would need another supreme court reevaluating previous court decisions in tandem with the current supreme court. This might allow for the transition into the new economic system regarding previous established law. 


\section{3b. Society Function}

We have discussed how supply and demand would work in a non-monetary economy. We have also discussed how government policy would work. Both sections have taken some assumptions into account, but it should be noted that not everything would be ideal. There would most likely be problems living in a non-monetary society. One of the main problems is boredom. It is possible that constant leisure would eventually become unwanted and the population would want something to do other than spending all their time on leisure. Some people could spend all day every day relaxing or working on hobbies. Many people want to work towards something meaningful. This is described in Maslow's Hierarchy of Needs as the fifth level of "Selfactualization". Self-actualization needs are classified as self-fulfillment and seeking personal growth and peak experiences(Mcleod, n.d.). This is to say that people seek to grow and do something meaningful and defining during their lives. It's possible that some work could be available for people to find fulfillment in their lives although the work would more of a personal project instead of a requirement.

The social platform would change drastically. As income isn't the primary driver for status in society it would likely be replaced by the fourth level in Maslow's Hierarchy of Needs "Esteem". The fourth level of Esteem has two categories: 1. Esteem for oneself and 2. The desire for reputation or respect from others. There would either be a social ranking based off esteem or there would be no social structure as items would no longer merit status. Status could come from artistic creation which is something AI has difficulty creating at present. It is possible that AI could create decent works of artistic expression in the future. Currently AI is programmed to "learn" a specific aesthetic by analyzing thousands of images and then creating art based on what it had learned(AI Is Blurring the Definition of Artist, 2018).

Normal life would also change drastically. With jobs no longer needing to be filled by labor, people could spend more time on things they enjoy doing. Many people don't do activities they enjoy in a monetary economy due to the job not paying enough to support a good lifestyle or the lifestyle they would want. With costs no longer part of the equation people would be free to explore options that were not available under normal circumstances. A life of leisure could lead to some societal risks such as the phasing out of previous knowledge or general laziness which could lead to health issues.

\section{Chapter 4: Conclusions}

This research discusses how the supply and demand functions of consumption goods, as well as governing policies need to be modified under a non-monetaty economy. So, could a nonmonetary economy ever become a reality? There are many obstacles. The first obstacle is the technology and methods needed to be in place to sustain a large population. This would need to be implemented years ahead of time to make sure it is reliable. The second obstacle is the perception from a monetary economy. People that have been in a monetary economy would not want to risk their own economy for something that might be better but might not work. The third obstacle, and possibly the largest one, is resource sustainability. As discussed in earlier sections, without resource sustainability the non-monetary economy would likely collapse. The economy can't handle unlimited wants with limited resources. There must be a way to keep resources 
coming in. It could be an advanced form of recycling or high energy production using matter conversion or some other futuristic principle. Whatever it is it needs to be able to keep up with the production otherwise the resources will deplete, and the non-monetary economy will collapse. Resource use and how sustainable those resources are is a major factor in a nonmonetary economy. Perhaps equally important is the method at which the economy is achieved.

This paper only covers the surface of a much deeper research topic that has not been studied too often. There are very few economists that study non-monetary economies when compared to the number of economists that study monetary economies. Further research into government and society behavior would be important areas to investigate. This, along with many other areas of non-monetary economies, would be unexplored territory when compared to the work on monetary economies.

\section{Bibliography}

AI Is Blurring the Definition of Artist. (2018, December 6). American Scientist.

https://www.americanscientist.org/article/ai-is-blurring-the-definition-of-artist

Bockman, J. (2011). Markets in the Name of Socialism. Stanford University Press.

Branches of Government | house.gov. (n.d.). Retrieved May 26, 2021, from

https://www.house.gov/the-house-explained/branches-of-government

Broderick, M.D., S. (n.d.). What Does Vaping Do to Your Lungs? Retrieved July 6, 2021, from https://www.hopkinsmedicine.org/health/wellness-and-prevention/what-does-vaping-doto-your-lungs

Chernoff, A., \& Warman, C. (2020). COVID-19 and Implications for Automation (No. w27249;

p. w27249). National Bureau of Economic Research. https://doi.org/10.3386/w27249

Commonwealth Parliament, C. (n.d.). The tools of macroeconomic policy-A short primer

(Australia) [Text]. Retrieved April 30, 2021, from

https://www.aph.gov.au/About_Parliament/Parliamentary_Departments/Parliamentary_Li brary/pubs/BriefingBook44p/MacroeconomicPolicy

Kolb, R. (2007). Encyclopedia of Business Ethics and Society. In Encyclopedia of Business

Ethics and Society (First, Vol. 1-5, p. 1345). SAGE Publications, Inc. 
Lichtenberg, B. W., Nick. (n.d.). Restaurants are starting to hire robots instead of people who are demanding higher pay. Business Insider. Retrieved July 6, 2021, from https://www.businessinsider.com/labor-shortage-automation-restaurants-hiringemployment-productivity-job-market-outlook-2021-7

Lucas, A. (2021, June 2). McDonald's is testing automated drive-thru ordering at 10 Chicago restaurants. CNBC. https://www.cnbc.com/2021/06/02/mcdonalds-tests-automateddrive-thru-ordering-at-10-chicago-restaurants.html

Marx, K., \& Engels, F. (1883). The Communist Manifesto. Pluto Press.

Mcleod, S. (n.d.). Maslow's Hierarchy of Needs. Simply Psychology. Retrieved April 30, 2021, from https://www.simplypsychology.org/maslow.html

Report-How Robots Change the World.pdf. (n.d.). Retrieved July 12, 2021, from https://cdn2.hubspot.net/hubfs/2240363/Report\%20$\% 20$ How $\% 20$ Robots $\% 20$ Change $\% 20$ the $\% 20$ World.pdf?utm_medium=email\&_hsenc=p 2ANqtz-S_yv5LZTWzdC5IER_NtS13PcknlmRKCRLWkiY7DXoc24tLeHNQmxbflluLCA4Prk WMen4_J_hWSH49WG3OQvHF61Jlg\&_hsmi=74013545\&utm_content=74013545\&ut m_source=hs_automation\&hsCtaTracking=07b1855a-24f4-4b99-bcb8b0d2a13b715e\%7C53b7a48e-9591-4179-8eab-694443190b4f

Semuels, A. (n.d.). Millions of Americans Have Lost Jobs in the Pandemic-And Robots and AI Are Replacing Them Faster Than Ever. Time. Retrieved July 12, 2021, from https://time.com/5876604/machines-jobs-coronavirus/

Yarlagadda, R. T. (2017). AI Automation and it's Future in the UnitedStates. 5(1), 8. 